\title{
Addictive agents and intracranial stimulation: Daily morphine and lateral hypothalamic self-stimulation
}

\author{
HAROLD D. BUSH, MARYANN F. BUSH, M. ANN MILLER, and LARRY D. REID \\ Bradley University, Peoria, Illinois 61606
}

\begin{abstract}
Rats were allowed to press for electrical stimulation of the lateral hypothalamus on days before, during, and after daily morphine or placebo injections. During tests $1 \mathrm{~h}$ after morphine injections, press rates were initially depressed at doses of $10 \mathrm{mg} / \mathrm{kg}$ or greater. As days of testing under daily morphine doses of 10 or $15 \mathrm{mg} / \mathrm{kg}$ continued, pressing gradually increased $1 \mathrm{~h}$ after injections. Four hours after morphine injections with doses of 10 and $15 \mathrm{mg} / \mathrm{kg}$, pressing rates were greater than rats' previous rates of pressing and control groups' pressing, and this facilitation did not wane across 20 days of injections. With termination of 20 days of injections, pressing rates generally returned to levels seen prior to days of injections. The facilitation of intracranial self-stimulation at $4 \mathrm{~h}$ after injections of moderate doses of morphine might reflect processes germane to morphine's positively reinforcing properties.
\end{abstract}

There is agreement that differential prosencephalic subcortical activity is critical to basic motivational processes (Grossman, 1966). Furthermore, many lines of evidence converge to support the idea that the lateral hypothalamic area (especially the medial forebrain bundle) is a part of a system the activity of which is positive emotionality (reward or positive reinforcement when delivered contingently) just as the geniculate, colliculus, and occipital cortex are parts of a system the activity of which is vision (Olds, 1962; 1969). Other lines of evidence converge to support the idea that the role of the central nervous system is paramount in addictive phenomena (Kerr \& Pozuelo, 1971; Myers \& Martin, 1973). Since many phenomena of addictions (e.g., high work output for addictive agents, subjective reports of craving, and relapse to taking addictive agents following withdrawal) are motivational phenomena, it follows that addictive agents might modify the organization of forebrain systems of emotion, motivation, and reinforcement (Collier, 1969).

Kerr and Pozuelo (1971) have specifically suggested that morphine dependence is the result of reorganization of hypothalamic nuclei of food-hunger regulation. They support their suggestion with data showing that lesions of the ventromedial nuclei of the hypothalamus attenuated withdrawal symptoms and enhanced sensitivity to morphine. Along the same lines, Glick and Charap (1973) report that lesions of the posterior medial forebrain bundle (PMFB) affected morphine addictions. They concluded, "The

Supported by NIDA Grant DA 01049 and by Bradley University's Board for Research which administered NSF Grant GU 3320. We thank Randy Hunsicker for his help in collecting data, and Dr. H. Richard Miller, now of Southern Illinois University, for his advice during the initial stages of the study.
PMFB lesion appears to separate mechanisms responsible for the initial addiction and later dependence to morphine; the lesion facilitates the former and, if equated for dosage, impairs the latter (Glick \& Charap, 1973, p. 348)." These conclusions contribute to a rationale for studying interactions between addictive agents and forebrain mechanisms. In animals chronically fixed with intracranial electrodes, an index reflecting the status of forebrain mechanisms of motivation and reinforcement is changing responsiveness to positively reinforcing intracranial stimulation (ICS). Consequently, it is of interest to determine the effects of addictive agents on intracranial self-stimulation.

Olds and Travis (1960) tested the effects of morphine (from about 5 to $10 \mathrm{mg} / \mathrm{kg}$ up to $2 \mathrm{~h}$ after injections) upon hypothalamic self-stimulation and found that morphine suppressed rates of selfstimulation. The results of Olds and Travis were not particularly surprising because morphine injections generally lead, soon after injections, to lethargy with regard to many activities. No other reports of morphine's effects on self-stimulation appeared until the reports of Adams, Lorens, and Mitchell (1972) and Lorens and Mitchell (1973). They found that self-stimulation rates were suppressed just after injections of 5,10 , and $20 \mathrm{mg} / \mathrm{kg}$ of morphine as would be predicted from the work of Olds and Travis. They also found, however, that self-stimulation rates were enhanced 3 to $6 \mathrm{~h}$ after injections. Lorens and Mitchell (1973) also provided data leading to the suggestion that it was unlikely that the facilitation in self-stimulation was due to an increase in general activity of the rats sometimes seen as morphine's depressing effects subside. The report of Adams et al. was published just as we were starting to test 
morphine's effects on self-stimulation, and we used their results to plan the following studies of the effects of morphine on hypothalamic medial forebrain bundle self-stimulation.

\section{EXPERIMENT I}

\section{Method}

Subjects. Under sodium pentobarbital anesthesia, 15 experimentally naive adult male Sprague-Dawley rats were each fixed with a bipolar stainless steel electrode (Plastic Products, No. 303) with tips aimed for the lateral hypothalamic medial forebrain bundle. Each electrode wire was insulated except at the cross section of its tip and the two wires of the bipolar electrode, twisted about one another, were separated only by their insulation. Subjects were selected from a larger number of subjects with electrodes on the basis of exceeding a criterion of 35 presses/minute for ICS with a minimum of artifacts such as seizures, forced movements, or long pauses between presses. At the time of surgery, subjects weighed from 300 to $\mathbf{4 0 0} \mathrm{g}$. Throughout the procedures, subjects were housed in individual cages with food and water always available.

Apparatus. Three nearly identical clear plastic experimental chambers $(24 \times 30 \times 35 \mathrm{~cm})$ were used. Each chamber was housed within a lighted sound-attenuating box. Through one side of each chamber extended a lever, the depression of which resulted in intracranial stimulation (ICS).

ICS was $60-\mathrm{Hz}$ sine waves of $30 \mathrm{microA}$ of $.5 \mathrm{sec}$ and was continually monitored with the aid of an oscilloscope as voltage drop across a fixed resistance. ICS was delivered by way of light, flexible leads connected to slip ring assemblies in the ceilings of the chambers. allowing for ICS delivery without hampering rat's movements.

Procedure. After allowing at least 5 days for recovery from surgery, subjects were tested in an experimental chamber different than those used throughout the balance of the procedures. This chamber of initial testing was a small box equipped with a lever, the depression of which yielded ICS. During these initial tests, intensities of ICS were changed periodically and subjects' responsiveness observed. Since all subjects pressed steadily at 30 microA, that intensity was used throughout the rest of the procedure.

After subjects and intensity of ICS were chosen, subjects began the following daily regimen of testing in the experimental chambers. Each subject was tested three times a day. Each test was $11 \mathrm{~min}$ in the chamber with the opportunity to press for ICS. The presses of tne 1st min were not recorded and served as a period for subjects to initiate pressing. If a subject did not begin pressing within the first 15 sec after it was placed in the box, a rare event, the experimenter delivered ICS while shaping pressing during the next $45 \mathrm{sec}$. All subjects, on every occasion, pressed some prior to the $10 \mathrm{~min}$ of measurement during which all leverpresses were recorded.

As mentioned, subjects were tested three times a day or at 10:30 a.m., 12:30 p.m., and 3:30 p.m. Injections, when scheduled, were given at 11:30 a.m. Consequently, a testing session was either 23,1 , or $4 \mathrm{~h}$ following injections.

Subjects were tested until their press rates stabilized. Then, subjects continued daily testing for 5 days, the daily sessions of baseline (the first 5-day block of testing). All subjects received injections during the next 20 days of testing (Blocks $2,3,4$, and 5 of testing). Five subjects received $10 \mathrm{mg} / \mathrm{kg}$ of morphine sulfate, five subjects received $15 \mathrm{mg} / \mathrm{kg}$ of morphine, and five subjects received the water carrier of morphine. It was arranged so that the volume of injections averaged $.5 \mathrm{ml} / \mathrm{kg}$, and all injections were subcutaneous. After termination of injections, subjects continued the regimen of daily tests for another 5 days (Block 6).

After the sixth block of testing, subjects were sacrificed, under large doses of anesthesia, by intracardial profusions of saline followed by Formalin. Eventually 75-micron frozen slices of the subjects' brains were inspected to determine the site of electrode tips. Brain slices were treated as photographic negatives, and the resulting images were enlarged and photographically recorded as aids in verifying the site of ICS (Guzman-Flores, Alcaraz, \& Fernandez, 1968).

When groups of rats are tested three times a day for 30 days, a considerable number of scores are generated which need to be summarized. To determine morphine's effects, two kinds of comparisons are needed: (a) press rates of subjects receiving morphine compared to press rates of placebo subjects and (b) press rates during morphine compared to rates of the same subjects prior to injections. To simplify comparisons across rats and, at the same time, to get an index of pressing compared to baseline pressing, mean scores of baseline were subtracted from scores of postbaseline. A difference greater than 0.0 indicates increased pressing, and a difference less than 0.0 indicates decreased pressing compared to mean baseline. To provide further data reduction and summary, mean differences scores were calculated for each 5-day block of testing.

\section{Results}

From the results of rats receiving placebo injections in this and similar studies (Bush, 1975, Experiment II; Terando, 1974), it can be concluded that pressing rates for ICS gradually increase across days of daily testing. Our results suggest that rats will press about $18 \%$ more during the last 5 days of a 30-day period of testing. Our results also suggest an overall increase of about $8 \%$ during the days in which the rats of these experiments got injections. Consequently, the expected results of daily testing without the influence of a drug is for pressing rates to increase, and when pressing rates decrease, it can be concluded that some effect has changed the expected results. When pressing rates are increased following an injection of a drug, it is necessary, before concluding that the drug facilitates pressing. to show that the level of increase is greater than what would have been expected from merely continuing testing.

Figure 1 presents the daily means of each of the three groups of subjects at the 4 -h measurement. The

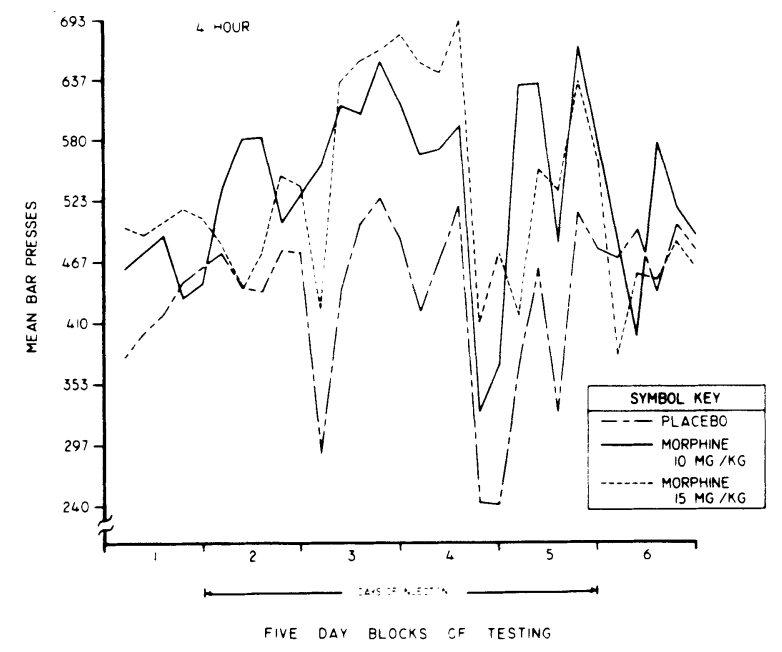

Figure 1. Daily means of each group of subjects at the measurement session corresponding to $4 \mathrm{~h}$ after injections. 

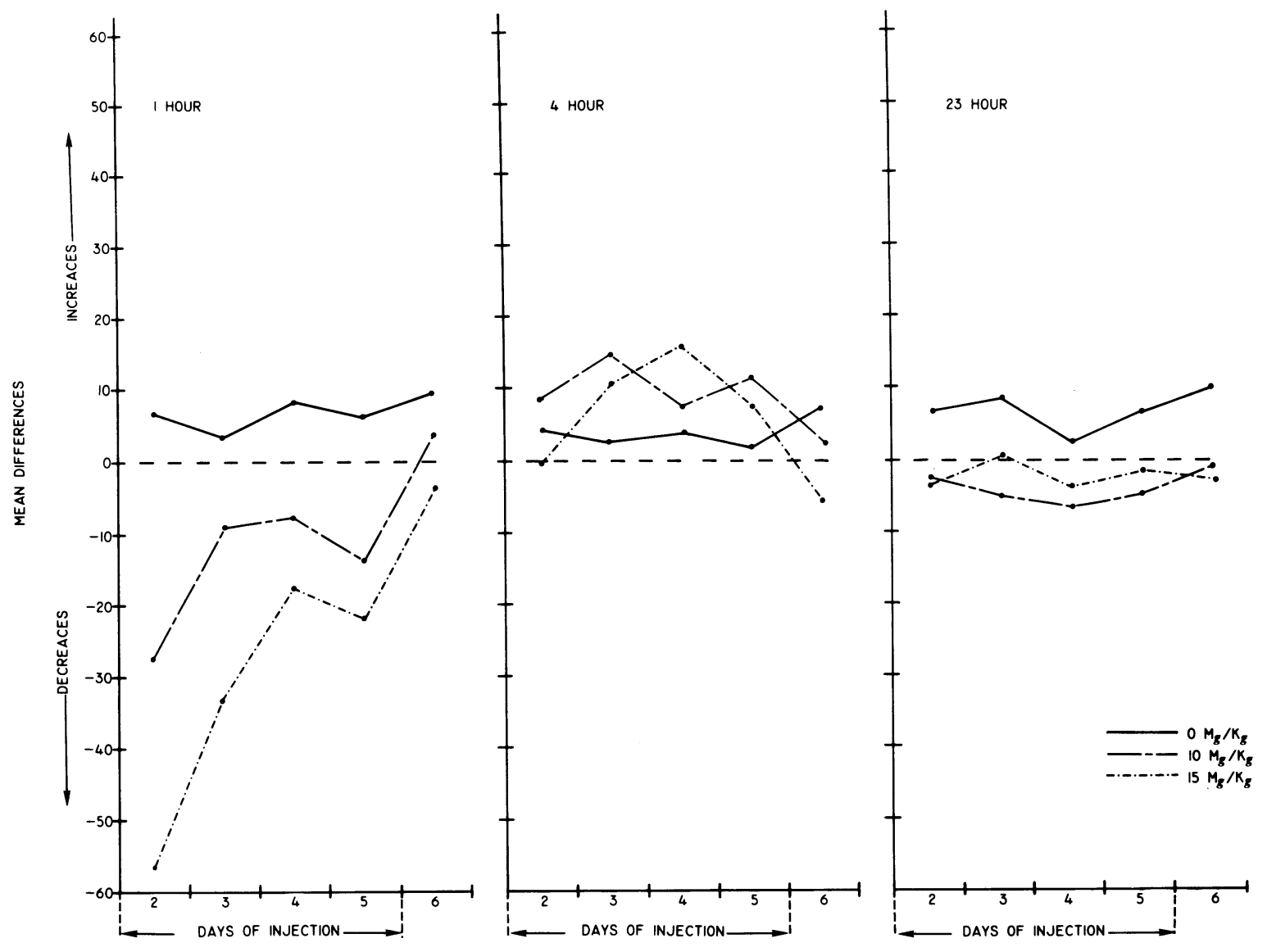

BLOCKS OF TESTING

Figure 2. Mean differences (score minus baseline) in presses per minute for blocks of 5 days of testing at 1-, 4-, and 23- h measurement sessions.

radical drop in pressing during the latter days of injections is due to an equipment failure and does not represent changes in responsiveness to ICS. Figure 2 presents the data of all three measurement sessions, and the middle panel of Figure 2 is a summary of data of Figure 1. The summary presented in Figure 2 excludes the data associated with the equipment failure; however, statistical analyses of data of Figure 2 reported here includes the data of equipment failures except where specifically mentioned.

Pressing under the influence of morphine $4 \mathrm{~h}$ after injections was, in general, greater than pressing prior to injections or rate of pressing anticipated from control subjects (Figure 1 and Figure 2, middle panel). Pressing under $10 \mathrm{mg} / \mathrm{kg}$ was facilitated with first injections and remained enhanced throughout the 20 days of injections. Pressing under $15 \mathrm{mg} / \mathrm{kg}$ of morphine was not facilitated until the 4th or 5th day of injections. Since there are other data showing no decline in pressing across the latter days of a 20-day injection period under $15 \mathrm{mg} / \mathrm{kg}$ (Farber \& Reid,
Note 1) and since rats of these tests generally maintained enhanced pressing rates, it can be concluded that subjects of $15 \mathrm{mg} / \mathrm{kg}$ also show facilitation of pressing throughout the latter days of 20 days of injections. On the 19th and 20th days of injections, rats of $15 \mathrm{mg} / \mathrm{kg}, 4 \mathrm{~h}$ after injections, pressed $29 \%$ and $14 \%$, respectively, more than baseline. An analysis of variance (ANOVA) of data of mean baseline scores provides no basis for concluding that groups of 0,10 , and $15 \mathrm{mg} / \mathrm{kg}$ differed from one another prior to injections $(F<1)$. A 3 by 4 ANOVA with repeated measures of subjects' mean block scores, adjusted by subtracting their mean baseline score, revealed a reliable difference among the three groups of this experiment during days of injections ( $F=30.7, \mathrm{df}=2 / 12, \mathrm{p}<.01$ ). Neither the factors of blocks of testing nor the interaction met standards of reliability (ps $>.25$ ).

Figure 2, left panel, shows that pressing $1 \mathrm{~h}$ after injections was less than base rates and less than the mean of control subjects' rates. As days of injections 
continued, the suppression of pressing was reduced. The dose of $15 \mathrm{mg} / \mathrm{kg}$ produced more suppression than did the dose of $10 \mathrm{mg} / \mathrm{kg}$.

Figure 2, right panel, presents data of $23 \mathrm{~h}$ after injections. Difference scores of subjects of morphine are less than scores of control subjects. Rate of pressing, however, is not much less than subjects' rates during baseline, except during Blocks 4 and 5 . A 3 by 4 ANOVA for repeated measures, using adjusted mean block scores, indicates that the press rates of the groups were reliably different from one another during 23-h tests $(F=3.95, \mathrm{df}=2 / 12, \mathrm{p}<.05)$, with subjects of morphine pressing less than the control group. Student $t$ tests for differences between correlated means of subjects of morphine indicated reliable differences of Blocks 4 and 5 from baseline for the $15 \mathrm{mg} / \mathrm{kg}$ group, and for Block 4 for the $10 \mathrm{mg} / \mathrm{kg}$ group: $15 \mathrm{mg} / \mathrm{kg}$, Block $4-\mathrm{t}=10.6$, $\mathrm{p}<.005$; Block 5-t $=3.4, \mathrm{p}<.01: 10 \mathrm{mg} / \mathrm{kg}$, Block $4-\mathrm{t}=2.29, \mathrm{p}<.05$. Such analyses indicate reliable reductions in pressing for morphine subjects during the latter days of testing at 23-h measurements.

One hypothesis to explain the reduced rates might rely on the fact that we had equipment failures during the latter days of testing. Consequently, we did a 3 by 16 ANOVA for repeated measures with the factors of the three groups and with the factors of daily tests, excluding the days of testing of equipment failures and days just before and just after those equipment failures to exclude any possibility of confounding the conclusions by faulty measurement. The scores of this ANOVA were adjusted by subtracting each subject's mean baseline score. The ANOVA yielded an $F$ for the group factor of $8.26 . \mathrm{df}=2 / 12, \mathrm{p}<.01$, indicating that subjects of morphine pressed reliably less than their control group.

With continuance of injections, evidently, rats of morphine are responding less $23 \mathrm{~h}$ after their daily injections than control groups and somewhat less than their base rates. When an overt seizure occurred during a measurement, which was rare among control subjects and during all baseline measurements, a session was lengthened or run again in order to not confound measurement by the time a subject was seizuring. Rats of morphine at $23 \mathrm{~h}$ after injections had more overt seizures than the control subjects (rats of control $=0$, rats of morphine $=29$ out of a possible number of 100 sessions a dose). Even though we attempted to correct for every instance of overt seizures, we may have missed ones of short duration; and, since more were occurring during the 23-h measurement, more might have been missed. The reduction in pressing at $2.3 \mathrm{~h}$ for subjects of morphine, therefore, may have been due to more seizures or it may have been due to less positiveness being generated by the ICS.

Pressing of morphine subjects was generally less than pressing of control subjects during days of

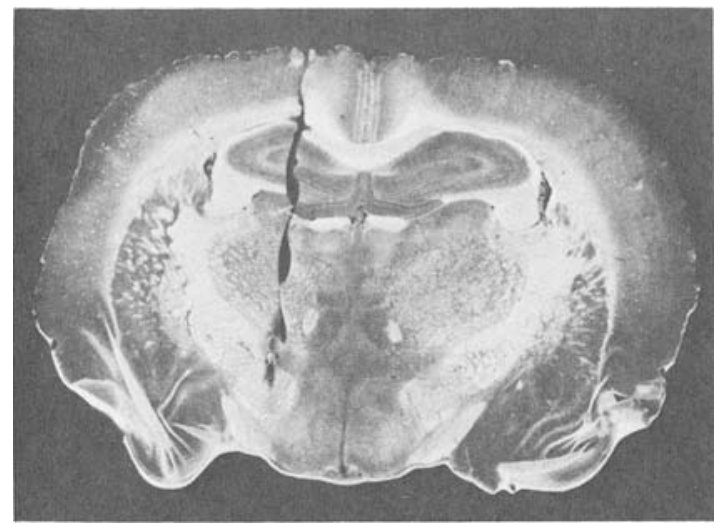

Figure 3. Photograph showing the typical location of an electrode.

post-morphine testing but very similar to pressing during baseline (Figure 2).

Fourteen of the 15 rats for which histological analyses were possible indicated that all electrode tips were in the lateral hypothalamus stimulating the medial forebrain bundle and area immediately surrounding it (Figure 3). All electrode tips were lateral to the fornix and medial to the internal capsule-crus cerebra and were, in general, in the same anterior-posterior planes as the ventromedial nucleus of the hypothalamus. Electrode tips varied in depth from the dorsal edge of the medial forebrain bundle to near the ventral edge (König \& Klippel. 1963). Even though electrode tips were in a relatively circumscribed area, the placements did vary. There was, however, no apparent correlation between shifts in pressing and other behavioral signs accompanying morphine injections and differences in site of electrode tip.

\section{DISCUSSION}

Rats with only placebo injections show a gradual but steady increase in pressing across daily self-stimulation tests. During days prior to formal testing when rats are given their first opportunities to press, the trend is for rats to increase their pressing, and sometimes the increases are quite dramatic. It is doubtful that mere practice at the manual task of pressing will account for the steady increases in pressing observed during the latter days of testing, because the rats by that time will have practiced pressing thousands of times and it would be expected that after a few days of practice that they would be manually efficient. The totality of events including repetition of ICS, in some way, seems to potentiate the rewarding value of the barpress. It should not be concluded, however, that such increases in rate of responding, with continuance of periodic opportunities to respond, is peculiar to behavior with ICS as 
the incentive. It is generally observed that engaging in a behavior seems to potentiate the motivation to engage in the behavior (Allport, 1937; Hill, Note 2). For example, Young (1973) reported data collected by Trafton showing that licking rates for sugar-water of a variety of concentrations increase across daily testing. Regardless of how ubiquitous it is for behavior to accelerate with periodic tests of that behavior, it is the case that before a conclusion is reached that morphine, or any other agent, potentiates daily self-stimulation rates, the increase under the agent must be greater than an anticipated increase due to the effects of repeated testing.

A subcutaneous dose of $10 \mathrm{mg} / \mathrm{kg}$ of morphine sulfate suppresses responding for lateral hypothalamic ICS $1 \mathrm{~h}$ after injections. This suppressive effect lessens with daily injections. At $4 \mathrm{~h}$ after injections, press rates for ICS are facilitated. During the latter days of testing, and $23 \mathrm{~h}$ after injections, pressing was slightly less than what would have been expected based on control groups' pressing. With doses of $15 \mathrm{mg} / \mathrm{kg}$, pressing changed similarly to pressing under the influence of $10 \mathrm{mg} / \mathrm{kg}$ except that the suppression seen $1 \mathrm{~h}$ after injections was greater and the facilitation seen $4 \mathrm{~h}$ after injections was not observed with the first injections. Interestingly, the facilitation in pressing, at $4 \mathrm{~h}$ after injections with these doses, did not wane across 20 days of injection.

Informal observations of the rats were interesting. Rats receiving either dose of morphine seemed to present themselves for injections and lay in the experimenter's hand without struggling when injected. Rats receiving placebo vigorously attempted to escape from injection and were therefore difficult to handle at the times of injection. The morphineinjected rats evidence stereotypic behavior. Their behavior was similar to the characteristic syndrome reported by Ayhan and Randrup (1972), a ritualistic behavior including gnawing at the wire mesh floor and biting at their paws. Two of the five rats receiving $10 \mathrm{mg} / \mathrm{kg}$ licked and bit at their paws until they caused abrasions as well as did two of five rats receiving $15 \mathrm{mg} / \mathrm{kg}$. One rat in the $15 \mathrm{mg} / \mathrm{kg}$ group gnawed near the site of injection to the extent of tearing the skin. Even though these behaviors seemed to match those described by Ayhan and Randrup (1972), we were concerned about this being a result of an interaction between daily ICS administration and daily injections of morphine. Consequently, we gave five rats which had no surgery nor electrodes 20 daily injections of $15 \mathrm{mg} / \mathrm{kg}$ of morphine and observed their tendencies toward stereotypic gnawing, licking, and paw biting. One of these rats developed sores from chewing its paws, and all rats evidenced stereotypic behaviors. Consequently, it was concluded that some rats receiving injections of morphine bite at their forepaws and body to the point of mutilation.

\section{EXPERIMENT II}

Rats of the first experiment received relatively small doses of morphine across a 20-day period. Each rat of this experiment was given a small dose of morphine the 1st day of injections, and the dose was increased each day across a 20-day period, resulting in heavy doses by the end of the period of daily injections.

\section{Method}

Twelve rats that pressed for lateral hypothalamic ICS were allowed to press in the apparatus three times a day corresponding to 1,4 , and $23 \mathrm{~h}$ after injections. All ICS was 25 microA of .5-sec $60-\mathrm{Hz}$ sine waves. Sites of stimulation were in the same area as sites of subjects of Experiment $I$.

The procedure was the same as that of Experiment I with the exceptions that test sessions were $5 \mathrm{~min}$ rather than $10 \mathrm{~min}$ and subjects received different doses of morphine. Throughout the 20-day injection period, four subjects received daily saline injections and eight subjects received morphine injections, subcutaneously. Four of the eight subjects received $5 \mathrm{mg} / \mathrm{kg}$ of morphine on the 1st day of injections, $10 \mathrm{mg} / \mathrm{kg}$ the $2 \mathrm{nd}$ day, and $15 \mathrm{mg} / \mathrm{kg}$ the $3 \mathrm{rd}$ day with daily increases of $5 \mathrm{mg} / \mathrm{kg}$ until on the 20th day of injection they received $100 \mathrm{mg} / \mathrm{kg}$. The other four subjects of morphine injections received $10 \mathrm{mg} / \mathrm{kg}$ on the 1 st day with $10 \mathrm{mg} / \mathrm{kg}$ daily increases in dose until they were receiving $200 \mathrm{mg} / \mathrm{kg}$ on the $20 \mathrm{th}$ day. Testing continued for 5 days after injections were terminated.

\section{Results and Discussion}

Results are depicted in Figure 4. Pressing $1 \mathrm{~h}$ after injections was suppressed, with the higher dose producing the most suppression except during the last block of tests during days of injection. Except during the 1st days of injections (Block 2), all pressing rates were suppressed at 4 and $23 \mathrm{~h}$ after injections compared to the rats' own base rates and compared to the rates of control subjects. With termination of morphine injections, the rats' pressing rates rose to levels similar to their base rates and rates of the saline-injected rats.

Throughout the series of morphine injections, rats steadily lost weight (from about $340 \mathrm{~g}$ to about $320 \mathrm{~g}$ ) and with termination of injections showed continued weight loss (from about $320 \mathrm{~g}$ to less than $310 \mathrm{~g}$ ). Subjects of saline injections showed a steady gain in weight across days of testing (from about $330 \mathrm{~g}$ to over $370 \mathrm{~g}$ ).

The first injections of morphine led to an enhancement of pressing $4 \mathrm{~h}$ after injections, as it did in Experiment I. Aside from the first few days of morphine injections, when low doses were given, self-stimulation was never enhanced under this schedule of increasing doses of morphine. This could have been the result of our not sampling enough periods after injections; however, it remains a possibility that we still would not have seen enhancement at other times. Those who study addictive phenomena as they give these steadily increasing doses may not be sampling the entire process, because the increasing doses limit the 

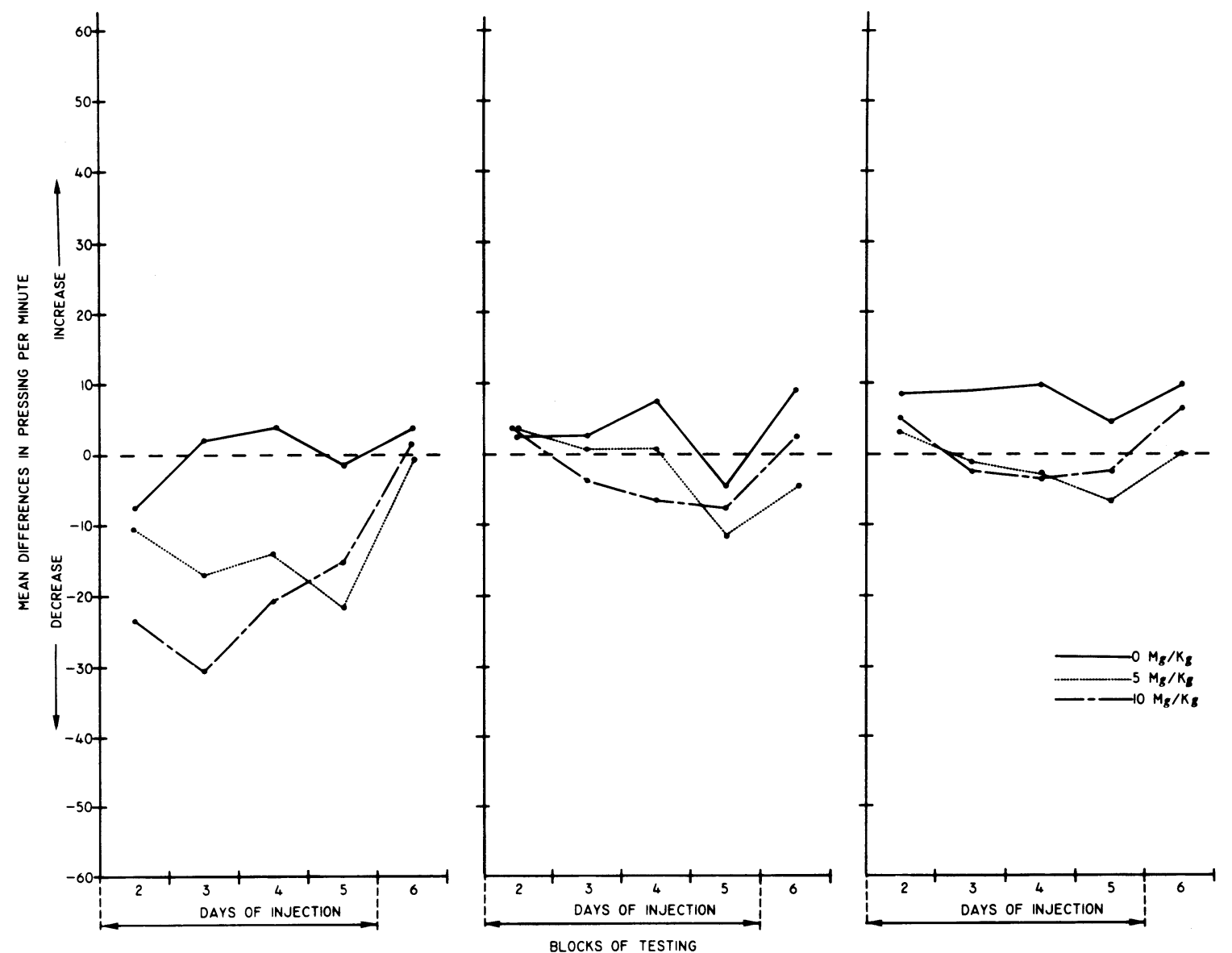

Figure 4. Mean differences (score minus baseline) in presses per minute taken during the 1-, 4-, and 23-h measurement sessions. The group labeled $5 \mathrm{mg} / \mathrm{kg}$ received $5 \mathrm{mg} / \mathrm{kg}$ daily increments of morphine and the group labeled $10 \mathrm{mg} / \mathrm{kg}$ received $10 \mathrm{mg} / \mathrm{kg} \mathrm{incre-}$ ments of morphine during days of injections.

processes that are reflected in the enhancement of self-stimulation.

\section{GENERAL DISCUSSION}

All reports of morphine's effects on lateral hypothalamic self-stimulation are congruent with one another. Morphine in large doses or shortly after injections suppresses rates of pressing (Adams et al., 1972; Lorens \& Mitchell, 1973; Olds \& Travis, 1960 and both experiments of this study). Morphine at certain doses and certain times after dosing, e.g., $10 \mathrm{mg} / \mathrm{kg} \quad 4 \mathrm{~h}$ after subcutaneous injections, accelerates lateral hypothalamic self-stimulation (Adams et al., 1972; Lorens \& Mitchell, 1973; Pert \& Hulsebus, 1974; and our Experiment I). Furthermore, $23 \mathrm{~h}$ after injections, after some days of daily dosing with moderate doses of morphine, press rates are slightly reduced and seizures due to the ICS become more frequent.

Across the experiments that have been done, a moderate variety of doses and times after dosing have been tested. What emerges is the inference that level of pressing is determined by a complex interaction of Size of Dose by Time After Dosing by Days of Daily Dosing. As days of dosing continue, the suppressive effects of morphine diminish and the facilitation effect is observed sooner after injections. The facilitation effect does not wane with continued testing across 20 days of testing, an observation confirmed by Pert and Hulsebus (1974).

Pert and Hulsebus (1974) reported that other opioids including heroin and methadone also facilitate self-stimulation. Addictive agents other than opioids, such as amphetamine, cocaine (Stein, 1964), and barbiturates (Reid, Gibson, Gledhill, \& Porter, 1964; Wasden \& Reid, 1968), also facilitate self-stimulation. In limited tests of dose-response parameters, ethanol at high doses suppresses rates of self-stimulation (St. Laurent, 1973) but may also facilitate self-stimulation at moderate doses (Vrtinski, Murray, \& Wolin, 1973; and recent results from our laboratory).

Morphine leads to supranormal levels of norepinephrine in subcortical brain (Gunne, 1963). Norepinephrine is a putative neurotransmitter of the 
medial forebrain bundle (Vogt. 1954: Stein. 1964). Consequently, it seems reasonable to suggest that morphine's facilitatory effect may be due to its ability to increase available neural norephinephrine. Pert and Hulsebus (1974) have shown that the facilitation effect was not diminished when serotonin levels were reduced by injections of $\mathrm{p}$-chlorophenylalanine but were reduced when catecholamine levels were reduced by injections of dl-alpha-methyl-tyrosine.

From this collection of data, the hypothesis is derived that morphine's, and possibly other addictive agents', positive reinforcing characteristics are due to the agents' capability of potentiating medial forebrain bundle activity, probably by increasing the functional levels of norepinephrine. The dose response relationship demonstrated across studies suggest that measurements of neurotransmitter levels will yield different results depending on a variety of factors including the complex interactions with respect to dose-response derived from these and similar data. It is indeed possible that this driving of the medial forebrain bundle system has some functional relationship to processes of establishment of addictions.

\section{REFERENCE NOTES}

1. Farber, P. D., \& Reid, L. D. Addictive agents and intracranial stimulation (ICS): Daily morphine and pressing for combinations of positive and negative ICS, in preparation.

2. Hill, W. F. Means and ends. Presidential address to the Midwestern Psychological Association Meeting, Chicago, 2 May 1975.

\section{REFERENCES}

Adams, W. J., Lorens, S. A., \& Mitchell, C. L. Morphine enhances lateral hypothalamic self-stimulation in the rat. Proceedings of the Society of Experimental Biology and Medicine, 1972, 140, 770-771.

Allport, G. W. Functional autonomy of motives. American Journal of Psychology, 1937, 50, 141-156.

Ayhan, I. H., \& RANDRUP, A. Role of brain noradrenaline in morphine-induced stereotyped behavior. Psychopharmacologia (Berl.), 1972, 27, 203-212.

Bush, H. D. Chronic morphine administration and hypothalamic intracranial stimulation. Unpublished master's thesis, Bradley University, 1975.

Collier, H. O. J. Humoral transmittors, supersensitivity, receptors and dependence. In H. Steinburg (Ed.), Scientific basis of drug dependence. London: Churchill, 1969. Pp. 49-66.

Glick, S. D., \& Charap, A. D. Morphine dependence in rats with medial forebrain bundle lesions. Psychopharmacologia (Berl.) 1973, 30, 343-348.

Grossman, S. P. A textbook of physiological psychology. New York: Wiley, 1966.
GUNNE. L. Catecholamines and 5-hydroxytryptamine in morphine tolerance and withdrawal. Acta Physiologica Scandinavica, 1963, 58. 1-19 (Supplementum 204).

Guzman-Flores. C.. Alcaraz, M., \& Fernandez, A. Rapid procedure to localize electrodes in experimental neurophysiology. Boletin del Institute de Estudros Medicos y Biologicos, Mexico, 1968, 16, 29-31.

KerR. F. L., \& Pozuelo, J. Suppression of physical dependence and induction of hypersensitivity to morphine by stereotaxic hypothalamic lesions in addicted rats. Mayo Clinic Proceedings, 1971. 46. 653-665.

KöNIG. J. F. R., \& KLIPPEL, R. A. The rat brain. Baltimore: Williams and Wilkens, 1963.

LoRens, S. A., \& Mitchell, C. L. Influence of morphine on lateral hypothalamic self-stimulation in the rat. Psychopharmacologia (Berl.), 1973, 32, 271-277.

MYERS, R. D., \& MARTin, G. E. The role of cerebral serotonin in ethanol preference of animals. In F. A. Seixas (Ed.), Alcoholism and the central nervous system. Annals of the New York Academy of Sciences, 1973, 215, 135-144.

Otds, J. Hypothalamic substrates of reward. Physiological Review's, 1962, 42. 554-604.

OlDs, J. The central nervous system and reinforcement of behavior. American Psychologist, 1969, 24, 114-132.

Olds, J., \& TRAvis, R. P. Effects of chloropromazine, meprobamate, pentobarbital, and morphine on self-stimulation. Journal of Pharmacology and Experimental Therapeutics, 1960, 128. 397.404.

Pert, A., \& Hulsebus, R. C. Opiate induced facilitation of self-stimulation behavior in the rat. Program and Abstract of the Society for Neuroscience, 1974. P. 372.(Abstract)

Reid, L. D., Gibson, W. E., Gledhill, S. M., \& Porter, P. B. Anticonvulsant drugs and self-stimulating behavior. Journal of Comparative and Physiological Psychology, 1964, 58, 317-320.

St. LAurent, J. Brain centers of reinforcement and effects of alcohol. In B. Kissin, \& $\mathrm{H}$. Begleiter (Eds.). The biology of alcoholism (Vol. 2): Physiology and behavior. New York: Plenum Press, 1973. Pp. 85-106.

Stein, L. Reciprocal action of reward and punishment mechanisms. In R. G. Heath (Ed.), The role of pleasure in behavior. New York: Hoeber, 1964. Pp. 113-139.

TERANDo, L. Effects of morphine on thresholds for intracranial reinforcement. Unpublished master's thesis, Bradley University, 1974.

VRTinski, P., MURray, R., \& Wolin, L. R. The effect of alcohol on intracranially reinforced response. Quarterly Journal of . Studies on Alcohol, 1973, 34, 718-725.

VoGT, M. The concentration of sympathin in different parts of the central nervous system under normal conditions and after the administration of drugs. Journal of Physiology, 1954, 123, 451-481.

WASDEN, R. E., \& REID, L. D. Intracranial stimulation: Performance decrements and a fear-reducing drug. Psychonomic Science, 1968, 12, 117-118.

Young, P. T. Emotions in man and animal (2nd ed.). Huntington, New York: Krieger, 1973.

(Received for publication August 20, 1975; accepted August 28, 1975.) 